1990 and 1999 corresponds to a quarter of a serving per day. In the nurses' health study and a companion cohort in men, the relative risk was 0.94 for an increase of one serving of fruit per day, which would predict a reduction of only $1-2 \% .^{3}$

\section{Comment}

The experience of Poland is consistent with epidemiological and clinical evidence ${ }^{4}$ indicating that mortality due to coronary heart disease can be reduced by partly replacing dietary saturated fats with polyunsaturated fats while maintaining a low intake of trans fatty acids.

Polyunsaturated fat reduces serum concentrations of low density cholesterol, ${ }^{4}$ but this cannot account for the size and rapidity of changes in coronary mortality in Poland. A higher intake of polyunsaturated fat also improves endothelial function, reduces platelet aggregability, and reduces ventricular fibrillation. ${ }^{4}$ The net effect can therefore be appreciated only by evaluating coronary end points. Increased intakes of polyunsaturated fat also probably explain most of the major declines in coronary mortality in the United States, United Kingdom, and Australia over several decades. ${ }^{5}$

Both omega 3 fatty acids and omega 6 fatty acids seem to contribute to reductions in coronary risk. ${ }^{4}$
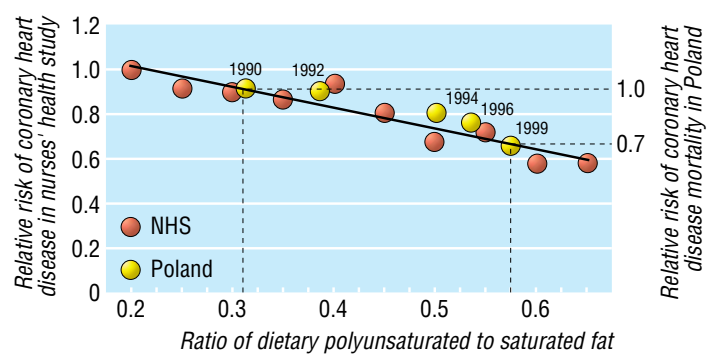

Ratio of dietary polyunsaturated to saturated fat and mortality due to coronary heart disease in Poland (relative to rates in 1990), superimposed on the relation between the fat ratio and coronary risk observed in the nurses' health study. Changes in dietary polyunsaturated to saturated fat in Poland between 1990 and 1999 are predicted to result in a $24 \%$ drop in coronary mortality, which is similar to the observed decline

\section{What is already known on this topic}

Mortality due to coronary heart disease fell drastically in Poland between 1990 and 1994

\section{What this study adds}

This decline has continued through 2002, with most of the decline probably resulting from a large increase in consumption of non-hydrogenated rapeseed and soya bean oil, rather than from reductions in smoking and an increase in fruit intake

According to statistics from the United Nations Food and Agricultural Organisation, ${ }^{\mathrm{w} 1 \mathrm{w} 2}$ the increase in polyunsaturated fat in Poland during the 1990s was primarily from rapeseed and to a lesser degree from soya bean oil; intake of omega 3 and omega 6 fatty acid would therefore have increased, making it difficult to distinguish their relative contributions to the drop in mortality. Statistics from the Food and Agricultural Organisation do not consider changes during processing; but a conscious effort was made in Poland to minimise the trans fat content of margarines made from these oils.

Contributors: Both authors contributed equally to this report and are joint guarantors.

Funding: Part funding from Health Evolution MonitoringClosing the Gap-Reducing Premature Mortality. Baseline for Monitoring Health Evolution Following Enlargement (European Union Grant Agreement No. 2003121).

Competing interests: None declared.

Ethical approval: Not needed.

Zatonski WA, McMichael AJ, Powles JW. Ecological study of reasons for sharp decline in mortality from ischaemic heart disease in Poland since 1991. BMJ 1998;316:1047-51

2 Hu FB, Stampfer MJ, Manson JE, Ascherio A, Colditz GA, Speizer FE, et al. Dietary saturated fats and their food sources in relation to the risk of coronary heart disease in women. Am J Clin Nutr 1999;70:1001-8.

3 Joshipura KJ, Hu FB, Manson JE, Stampfer MJ, Rimm EB, Speizer FE, et al. The effect of fruit and vegetable intake on risk of coronary heart disease. Ann Intern Med 2001;134:1106-14.

$4 \mathrm{Hu} \mathrm{FB}$, Willett WC. Optimal diets for prevention of coronary heart disease. JAMA 2002;288:2569-78.

5 Dwyer T, Hetzel BS. A comparison of trends of coronary heart disease mortality in Australia, USA, and England and Wales with reference to mortality in Australia, USA, and England and Wales with reference to
three major risk factors-hypertension, cigarette smoking and diet. Int J Epidemiol 1980;9:65-71.

\title{
Commentary: Will Europe's agricultural policy damage progress on cardiovascular disease?
}

\author{
Karen Lock, Martin McKee
}

European Centre on Health of

Societies in

Transition, London School of Hygiene and Tropical Medicine, London WC1E 7HT

Karen Lock research fellow Martin McKee professor

Correspondence to: K Lock karen.lock@ lshtm.ac.uk
Trends in cardiovascular disease in Europe have shown an east-west divide for over 30 years. Rapid declines in the European Union contrast with stagnant or rising trends in Russia and central and eastern Europe, with some notable exceptions, such as Poland and the Czech Republic, where rates have fallen since the 1990s. ${ }^{12}$ These improvements are attributed primarily to improved nutrition, ${ }^{12}$ which can be traced to the economic transition that followed political change in the late 1980s.

In Poland many food subsidies, in particular for animal fats, were abolished. Wider availability and lower prices for unsaturated fats and fruits caused rapid dietary changes. Zatonski and Willett explore the impact of these changes, suggesting that the reduction of over a third of coronary heart disease in Poland between 1990 and 2002 can be attributed mainly to increased consumption of polyunsaturated fats, with sustained reduction in saturated fats. ${ }^{1}$ They estimate that the small reduction in smoking and the increase in the intake of imported fruit have made little impact on cardiovascular disease.

The paper clearly shows that dietary change had a major impact on cardiovascular mortality, but the 
authors, by considering changes in the intake of imported fruit only, have underestimated changes in consumption of the full range of fruits and vegetables known to have significant cardioprotective effects. ${ }^{3}$ The introduction of a market economy had major consequences for domestic production and the retail sector. There has been large investment in agriculture, with central European producers now integrated with wider European agricultural production. Much nontraditional produce is now grown locally, and fruits and vegetables are available to consumers throughout the year. Consequently, to capture the full impact of changing availability of food since the 1990s, the changes in both the total and the seasonal consumption of all fruits and vegetables need to be taken into account.

Zatonski and Willett also show that it is possible to achieve quite remarkable reductions in deaths from cardiovascular disease over a short period. Yet, in Poland, this has been achieved mainly by economic and agricultural policies, and not health policies. In contrast, policies advocated by health ministries, exemplified by the English white paper Choosing Health (www.dh.gov.uk), remain focused on medical models of education and behaviour change, even though these have had little impact on rising rates of unhealthy diets and obesity.

The health gains achieved in Poland, however, may be threatened. The European Union's Common Agricultural Policy, introduced in the 1950s, is a major determinant of what people in Europe eat ${ }^{4}$ but fails to produce the range of foods that would allow the EU population to meet basic healthy eating guidelines. ${ }^{5}$ As Poland and others implement the Common Agricultural Policy-following accession to the EU in 2004they risk suffering the consequences of policy that places large scale agricultural production and economics above health. Studies in some countries, such as Slovenia and Sweden, have shown numerous adverse health effects of the Common Agricultural Policy, including the externalised costs on non-communicable diseases and obesity through subsidies for production and consumption of animal fats, tobacco and alcohol, and insufficient supply of fruits and vegetables. ${ }^{5}$ Reform of the policy is again high on the political agenda. However, current debates about the EU budget between the UK prime minister, Tony Blair, and the French president, Jacques Chirac, are characterised more by political horse trading than the possibility of supporting poor and rural populations while also improving the diet and health of all Europeans.

Competing interests: None declared.

\footnotetext{
1 Zatonski W, Willett W. Changes in dietary fat and declining coronary heart disease in Poland: population based study BMJ 2005;331:187-8.

heart disease in Poland: population based study BMJ 2005;331:187-8. trends in cardiovascular disease risk factors in the Czech Republic, 19851992. J Epidemiol Community Health 1997:51:272-7.

3 Lock K, Pomerleau J. Fruit and vegetables in the European Union: its effect on the burden of cardiovascular disease. Brussels: European Heart Network, 2005.

4 Lock K, ed. Integrating public health with European agriculture and food policy. Eurohealth 2004;10(1):1-30.

Lobstein T. Suppose we all ate a healthy diet? Eurohealth 2004;10(1): 8-12.
}

\title{
Lung cancer mortality at ages 35-54 in the European Union: ecological study of evolving tobacco epidemics
}

\author{
Joanna Didkowska, Marta Manczuk, Ann McNeill, John Powles, Witold Zatonski
}

Epidemiological analyses indicate that disease attributable to smoking is a leading contributor to the large gap in premature mortality between the 15 countries that formerly made up the European Union and the new member states from central and eastern Europe. ${ }^{1}$ However, the prevalence of smoking in most countries has not been measured in a sufficiently consistent way, or over a long enough period, to be used to predict trends in diseases caused by smoking.

\section{Participants, methods, and results}

Lung cancer mortality can provide a useful measure of a population's exposure to smoking, ${ }^{23}$ especially the population segment aged 35-54, when around 80-90\% of cases are caused by smoking. We used trends, for each sex, in age standardised mortality due to lung cancer for ages 35-54 to map the lagged effects of the smoking epidemic in the 15 original EU member states and new members from central and eastern Europe, and to infer the earlier trends in tobacco exposure. We calculated death rates, using five year age groups, from deaths attributed to lung cancer in national data and population estimates submitted to the World Health
Organization (http://www3.who.int/whosis/mort/text/ download.cfm?path $=$ whosis,mort,mort_download\& language $=$ English $)$.

Most EU countries, including all new member states from central and eastern Europe, are now experiencing falling death rates from lung cancer in men. Four countries are, however, exempt from this favourable trend: Portugal, Greece, Spain, and France show no evidence of a decline across the 35-54 age range (figure).

Mortality from lung cancer in women is still rising in most EU countries, except for the United Kingdom and, to some extent, Ireland and Denmark. The greatest increases in the past decade were observed in France, Spain, and Hungary; the estimated annual percentage changes are $7.2 \%, 6.8 \%$, and $6 \%$, respectively. In Latvia, Lithuania, Spain, and Portugal, death rates due to lung cancer remain very low. Rates for women in Hungary exceed those for women in all other member states (mirroring those for Hungarian men) and also exceed the rates for men in more than half the states in the EU. In three countries, lung cancer rates among women are the same as or higher than those
Cancer

Centre-Institute of Oncology, Cancer Epidemiology and Prevention Division, 5 Roentgena Str, 02-781 Warsaw, Poland

Joanna Didkowska senior research fellow Marta Manczuk junior research fellow Witold Zatonski director

University College London, London WC1E 6BT

Ann McNeill honorary senior research fellow

Department of Public Health and Primary Care, Institute of Public Health, Cambridge CB2 2SR

John Powles senior lecturer Correspondence to: W Zatonski canepid@coi.waw.p

BMJ 2005;331:189-92 